\title{
Pre-service Teachers' Awareness and Attitudes on South Korea's Increasing Cultural and Ethnic Diversity and the Role of Multicultural Education in K-12 Schools
}

\author{
Sunnie Lee Watson \\ Ball State University, United States \\ E-mail: slwatson@bsu.edu \\ Gilbert C. Park \\ Ball State University, United States \\ E-mail: gilbertcpark@gmail.com
}

Hong-soo Lee

Korea National University of Education, South Korea

E-mail: hongslee@knue.ac.kr

Received: July 10, 2011 Accepted: August 2, 2011 DOI: 10.5296/ije.v3i2.709

\begin{abstract}
As the number of multicultural students in South Korean schools continues to grow, activists and educators argue that South Korean schools are not meeting the needs of both multicultural and mono-cultural students and advocate for multicultural education. While educational literature looks at the meaning of multicultural education and how it can be implemented in the South Korean context, relatively little attention has been given to pre-service teachers' understanding of cultural diversity and multicultural education. This paper explores how South Korean pre-service teachers understand the increasing ethnic and cultural diversity in South Korean society and multicultural education in South Korean schools. The responses suggest that multicultural education for pre-service teachers should facilitate a critical examination of South Korean identity as a political construct. Furthermore it should empower them to actively define multicultural education in their own contexts as a way to politically engage multiculturalism in and out of school.
\end{abstract}

Keywords: Diversity, Multicultural education, Teacher Education, South Korean education 


\section{Introduction}

People finger pointed at me and my mom saying, "the dad is an American G.I."

They whispered behind my back. ... . Although I was young, I could see my mother's sadness.

I was ashamed, [because I thought it was] all my fault!

I scrubbed my face each day with white soap. My tears were melting that white soap. I hated my dark skin. Why does the world judge me?

(From the 2007 song, Black Happiness by Mi-Rae Yoon)

Mi-rae Yoon is a songwriter and singer whose song has shed light on some of the difficulties facing young people from a multicultural family background in Korea's historically homogeneous society. Yoon's family is what the Ministry of Education and Human Resources (MEHR, 2008) calls multicultural, where one or both parents are a different ethnicity than Korean. According to MEHR (2008), there were 18,778 multicultural students enrolled in South Korean primary and secondary schools in 2008, and this represents a 300 percent growth in just three years from 6,121 in 2005. The growth of multicultural students will likely continue with the steady influx of immigrants and migrant workers over the past two decades (Kong, Yoon, \& Yu, 2011; Lee, Seol, \& Cho; 2006; MEHR, 2008). In response to concerns regarding human rights and the rapidly changing demographics in South Korea, an increasing number of South Korean activists and educators (Kang, 2010; Lim, 2010, 2008; Park, 2007) advocate for multicultural education in K-12 schools and argue that South Korean schools fall short in meeting the needs of both multicultural and mono-cultural students. A growing body of literature looks at what multicultural education is and how it should be implemented in South Korea; however, relatively little attention has been placed on pre-service teacher training for understanding diversity and multiculturalism in South Korea.

With this in mind, this study explores how multicultural education is understood by South Korean pre-service teachers as a tool to better prepare their students for an increasingly multicultural society. The article starts with a review of relevant literature, theoretical framework and methodology. These are followed by a discussion on the survey results of a group of South Korean pre-service teachers, regarding (a) their perspectives of multicultural issues in South Korean society and schools, (b) their perceptions of multicultural approaches to education, (c) their sense of preparedness regarding teaching in a diverse setting, and (d) their desired preparation, training or support to be effective multicultural educators.

Based on the study results, we argue that multicultural education for pre-service teachers must foster critical examination of South Korean identity as a political construct and empower them to actively participate in the political process to address the needs of today's South Korean students. 


\section{Background Literature}

\subsection{Increasing Diversity in South Korea}

A changing demographic is most visible with the influx of immigrants to South Korea. Lim (2010) reports, for instance, that the number of non-South Koreans living in South Korea increased 2000 percent to one million in 2007 from 50,000 in 2006. Roughly 350,000 migrant workers came to South Korea from other parts of the world in search of better economic opportunities and now account for a large portion of the non-South Korean residents. The majority of them choose to stay longer illegally, while some obtain permanent residency through marriage to South Korean citizens (Park, 2007). Another significant group that has been growing since the 1990s is non-South Korean spouses of South Korean men in rural villages. Lee, Seol, and Cho (2006) explain that the uneven ratio between the genders due to South Korean families' preference for boys and women's preference for an urban lifestyle has led to many South Korean men in rural areas being unable to find partners. With support from local governments, these men sought wives from other parts of the world and the number of these immigrant wives increased rapidly over time. In 2005, Lee, Seol, and Choi (2006) found that nearly 14 percent of all marriages in South Korea included a non-South Korean citizen.

Adding to the number of non-South Korean residents, there are those who are culturally different from mainstream South Koreans. Among them are the defectors from North Korea. Because of South Korea's territorial claim over the entire peninsula, the refugees from North Korean are technically South Korean citizens. However, the generations of separation between communist North and capitalist South has left them culturally different from one another. While the number of North Korean refugees is relatively small at roughly 10,000, the economic and political instability of North Korea and the possibility of unification have caused the number to increase tremendously over time. Similarly, there are approximately seven million ethnic South Koreans living abroad, some of who return to South Korea to find themselves culturally and socially isolated, as is the case for many ethnic South Koreans from China and Japan. Moreover, there are so-called "mixed-blood children” like Mi-rae Yoon who struggled against South Korean biases over both physical and cultural differences (Choi, 2010; Park, 2005; Yoo, 2007; Yoon, 2004).

\subsection{Multicultural Education in South Korea}

Kang (2010) explains that difficulties like discrimination facing the immigrant adults in the workforce and the community are tied to "the school experiences of their children in terms of academic difficulties and social alienation (p. 293).” Studies (Oh, 2005; Sul, Han \& Lee, 2003) report, as an example, that limited fluency in Korean of many immigrant mothers negatively affects the linguistic and cultural development of their children. Coupled with the students' inability to obtain help with assignments at home, Kang (2010) reports that multicultural students are more likely to be labeled as learning-disabled. Wangtta, or group exclusion, is a form of social punishment received by roughly 13 percent of South Korean elementary students by their classmates (Lee, 2002). Sul, Han, and Lee (2003) estimate that wangtta is much more common for multicultural students as 30 percent of the survey 
respondents reported having experienced it and many of them identified that having a foreign mother was the reason for the social punishment. These struggles may have contributed to a three times higher drop out rate of multicultural students compared to mainstream South Korean youth (Kang, 2010).

In response, the South Korean government started funding numerous activities and programs, such as after-school programs, to assist multicultural students and their families with both academic and social integration into both South Korean schools and society. The Ministry of Education, Science and Technology (MEST) in 2008 termed these efforts as multicultural education and reported three specific goals. These are; (a) to reduce the educational disadvantages imposed on multicultural family students and to help them adapt to South Korean society, (b) to promote cultural sensitivity and understanding among general students, and (c) to assist students from multicultural families in becoming globally competent and bilingual. MEST's multicultural education, however, is being scrutinized by a number of South Korean educators (Choi, 2010; Kang, 2008; Lim, 2010). For instance, Kang (2008) argues that the approach assumes that the problem lies with the inability of the multicultural students to cope with school life; therefore, supplementary programs can fix these problems. Similarly, Lim (2010) explains that the approach does not take into consideration that the problem may lie with the school and the society, which makes it difficult for the students to feel included. Also, Choi (2010) argues that the real problem lies with the notion of "we Koreans" that excludes those who are not ethnically and culturally South Korean as legitimate members of the society.

For instance, South Koreans take great pride in their genetic and cultural homogeneity as Danil Minjok (one-blood ethnicity). This pride in Danil Minjok has been maintained in the early grades and reinforced throughout K-12 schooling. The underlying idea is that legitimate, real Koreans are both culturally and genetically, Danil Minjok, and not-so-real Koreans, on the other hand, are lesser Koreans that do not share the "purity" of South Koreans. Consequently, not-so-real Korean students face marginalization in schools. Multicultural education in South Korean education must be more than academic and social help in order to have a lasting and positive impact on the school experiences of both multicultural and mono-cultural South Korean students. The collective process of schooling and the mindsets of teachers and administrators, rather than the students themselves, is the key to addressing the challenge.

\subsection{Pre-service Teachers'Views towards Multicultural Education}

Missing in the literature, however, is discussion pertaining to the pre-service teachers' attitudes toward the issue of diversity and multicultural education in South Korea. While there is insufficient literature on this topic, Sleeter's (2008) observations on white pre-service teachers' attitudes on these issues are useful here. For instance, she found that white pre-service teachers, as members of the dominant group, did not recognize racial inequity as a major problem in today's schools. Also, they placed the blame for academic difficulty on the students of color and had lower academic expectations for them. Third, they preferred a colorblind approach to teaching and underplayed the significance of race. Lastly, many of 
them normalized their own culture, using it to compare and contrast others. Regarding pre-service South Korean teachers, Sleeter's (2008) finding suggests that, as members of the "we Koreans" group, they are less likely to recognize the problem of inequity facing multicultural students and more likely to hold deficit views and lower student expectations. They are also less likely to consider "we Koreans" as a problem and more likely to locate the problem on the multicultural students' differences.

\section{Theoretical Framework}

Our understanding of multicultural education for South Korean pre-service teachers is informed by critical multiculturalism that aims for social justice by confronting and disrupting the issue of inequity (Castro, 2010; Gorski, 2006; Gay, 1995; Sleeter \& Grant, 2007;). This view of multicultural education locates the problems facing multicultural students in South Korea beyond the confines of the school into the power relations between the oppressors and the oppressed. In other words, their academic and social marginalization in schools ultimately serves to maintain the privilege of "we Koreans."

Castro (2010) argues that critical multiculturalism requires “conscious reflections” where educators examine their own worldview to recognize the influence of their own life experiences in shaping these views. This serves to challenge the universality of the "right" way to live and fosters an appreciation for diversity around their own lives as well as their students' (Castro, 2010; Freire, 1999; Villegas \& Lucas, 2002). Critical reflections, Castro (2010) further explains, must be coupled with what Freire (1999) calls, "critical consciousness" where teaching is viewed as a political act so that the educators can locate their own teaching in relation to power.

The assertion is that education is political in nature as it can serve as a tool of the oppressors to facilitate their dominance, but, it can also empower the oppressed to resist the oppression as educators and students work together to transform the society towards social justice (Freire, 1999; Kinchloe, 2008). This perspective resists viewing students as "receiving objects" of leaning but instead promotes active learning where teachers and students teach and learn together through democratic social relations. It also critiques and challenges what Freire (1999) calls the "culture of silence" that instills negative and suppressed self-images of the oppressed that work to allow social injustices in schools and society. One way to do this, Kincheloe (2002, 2008) argues, is for educators to examine their own positionalities to the power relations as a way to become active members of the community for social change. The goal is for educators to examine how schooling plays a role in maintaining the power relations that marginalize their students both in and out of their classroom and explore ways to disrupt oppression with the students (Castro, 2010; Freire, 1999; Gorski, 2006; Rogriguez \& Berryman, 2002).

In other words, critical multiculturalism requires pre-service teacher education in South Korea to challenge directly the notion of "we Koreans" as a cultural and social construct with political implications. This is achieved by providing opportunities for the pre-service teachers to examine the meanings of terms like Korean, and how it works to privilege and disadvantage themselves and those around them while exploring ways to re-construct the 
term Korean as a group to include multicultural students in Korea. This would better prepare them, as educators, to work with students as members of a learning community. Together they could challenge the power relations labeling some as less-than-authentic-Koreans and resist social injustice in the larger society.

In focusing on the South Korean pre-service teachers, we also look for instances of what Rodriguez (1998) calls, "resistance to ideological change," where a pre-service teacher does not feel the need or desire to alter one's beliefs or value system. This is where a pre-service teacher believes that teaching is apolitical and refuses to consider the possibility that one's teaching may play a role in maintaining the notion of "we Koreans". We also anticipate "resistance to pedagogical change" where one refuses to "change her or his perception of what constitutes being an effective teacher (Rodriguez, 2008, p. 616)." With this, a South Korean pre-service teacher may define "good" teaching to mean effective delivery of lessons without considering critical engagement and empowerment as factors.

\section{Methodology}

\subsection{Research Questions}

The purpose of this study was to examine pre-service teachers' awareness of the newly emerging multicultural society in South Korea and their perspectives on multicultural education for addressing the issues in South Korea society. With this in mind, the research questions were:

1) Are South Korean pre-service teachers enrolled in a national teacher training university aware of the multicultural issues in South Korean society and education?

2) How comfortable are South Korean pre-service teachers with the multiculturalization of South Korean society? Do pre-service teachers have any attitudes or perceptions of South Korean society that may prevent them from being competent in using multicultural approaches in education?

3) What attitudes and perspectives do South Korean pre-service teachers have about multicultural education?

4) How prepared do South Korean pre-service teachers feel about teaching in classrooms with diversity and addressing multicultural issues? What kinds of preparation, training or support do pre-service teachers want for using multicultural approaches in the classrooms?

\subsection{Instrument \& Participants}

A survey instrument that included both multiple-choice questions and open-ended questions was developed based on a review of the literature, member-checking, and peer-debriefing with in-service teachers, school administrators and teacher educators in South Korea.

A total of twenty questions were selected for the survey questionnaire, combining multiple-choice and open-ended survey questions. Fourteen multiple-choice questions included participant demographic items and Likert scale questions (Vogt, 2007). Six 
questions were purely open-ended survey questions that encouraged participants to share their personally meaningful stories, thoughts and perspectives about the multiculturalization of Korean society and multicultural education in Korean education.

Participants in the study were pre-service teachers at a national teacher training university in South Korea during the 2010 academic year. This national teacher education university is among the most highly ranked teacher education institutions in South Korea and provided full government scholarships, including boarding on campus, to all students. Consequently, admission to the school is highly competitive, and students trained at this school are considered leaders in the teaching profession.

82 pre-service teachers volunteered to participate in the study at the mid-point of their education degrees. There were participants from the undergraduate education program and the graduate level teacher certification program, and therefore the age range varied from 19 to 39. Among the undergraduate level teacher education program, all but six participants (two in their first year and four in their fourth and last year in the program) were in their third year of their educational degree programs. In the graduate level teacher certification program, all but two were in the third semester of teacher training. There were 70 female participants and 12 male participants.

\subsection{Data Collection \& Analysis}

Pre-service teachers in the teacher education program at a national teacher training university in South Korea completed the survey questionnaire about the newly emerging multicultural society in South Korea and their perspectives on multicultural education in South Korea. The questionnaires were distributed to the pre-service teachers (who were willing to volunteer) during breaks in between classes and were collected after class throughout the spring semester of 2010 at the national teacher education institution.

The multiple-choice questions from the survey questionnaire were analyzed as nominal and ordinal data (Fowler, 1989), putting participants into ordered or unordered categories. The ones that were numerically calculated were charted. Qualitative data from the open-ended questions were analyzed using grounded theory guidelines and method of inquiry (Glaser \& Strauss 1967). Using the grounded theory approach encouraged the researchers engaged in this study to synthesize and interpret the written data to portray our understanding of the survey responses. The approach also guided us to present interpretations of relationships showed in the data, create statements about the implications of our analyses, and ultimately helped us to understand the studied phenomenon of the South Korean pre-service teachers understanding of the new multicultural society and education (Charmaz, 2005; Denzin \& Lincoln, 2005).

\section{Results}

Responses to our multiple-choice and narrative survey instrument indicate that most pre-service teachers are aware of the recent trend toward diversity in South Korean society and feel ambivalent about this change. The responses also show that pre-service teachers think that it is important for the South Korean government to find effective ways to support 
teachers so they can educate students about multiculturalism in schools. As future professionals, they were interested in using multicultural approaches in their classrooms and offered suggestions for training teachers to be successful in doing so. These responses and narratives also indicated that the pre-service teachers felt highly unprepared and unsupported for these tasks and showed low self-confidence in their ability to effectively face the diversity as teachers.

5.1 Research Question 1. Are South Korean pre-service teachers enrolled in a national teacher training university aware of the multicultural issues in South Korean society and education?

In order to examine research question 1, we asked whether pre-service teachers felt immigrant workers, illegal immigrants or internationally married people were treated well in South Korean society. Over 71 percent of the respondents responded that they felt that these people were treated poorly $(60.5 \%)$ or very poorly $(11.1 \%)$ in South Korean society. Only 28.4 percent thought that they were treated well (24.7\%) or very well (3.7\%).We also asked if pre-service teachers had any experience with students or children from multicultural families, either in daily life or in teacher training, and how they perceived the children's academic achievement and school life. Around 70 percent of respondents indicated that they had no experience. Among those who said they had experience, responses showed that pre-service teachers thought that students from multicultural families struggled in schools, both in academic achievement and school life, but more so in academic achievement.

Table 1. Responses for questionnaire item: Do you have any experience in working with students or children from multicultural families? How were their academic achievement and school life?

\begin{tabular}{|c|c|c|c|c|c|c|}
\hline & Very high & High & Average & Low & Very low & $\begin{array}{c}\text { No } \\
\text { experience }\end{array}$ \\
\hline $\begin{array}{c}\text { Academic } \\
\text { Achievement }\end{array}$ & $3.8 \%(3)$ & $1.3 \%(1)$ & $10.0 \%(8)$ & $11.3 \%(9)$ & $1.3 \%(1)$ & $72.5 \%(58)$ \\
\hline $\begin{array}{c}\text { Ability to } \\
\text { Function in } \\
\text { School }\end{array}$ & $5.3 \%(4)$ & $3.9 \%(3)$ & $14.5 \%(11)$ & $5.3 \%(4)$ & $1.3 \%(1)$ & $69.7 \%(53)$ \\
\hline
\end{tabular}

Participants also wrote personal narratives about their experiences with children from multicultural families. Their experience and responses varied to a large degree. Most respondents listed their experience with multicultural children as very limited: attending one seminar that was offered at school about multicultural families, hearing about these children in the media, traveling or volunteering for missionary work to different countries, doing volunteer work at community centers or churches, or learning about multicultural education in educational foundations or philosophy courses.

Nine of the 82 respondents shared their personal experience of participating in a multicultural mentoring program at the university. The university had been developing a K-12 school-based mentoring program for multicultural students in collaboration with several other 
universities and with the support of the South Korean government. This government-led program facilitated pre-service teachers to go into K-12 schools in the format of fieldwork experiences. They were supported in meeting and mentoring children from multicultural families.

The pre-service teachers who participated in the program indicated that although they were rather disappointed with the fact that they were only able to meet the children once or twice during the entire program, the experience with the program left them with a strong impression. They reported that the program helped them to develop strong commitments towards multicultural education and a sense of responsibility as teachers to ease the struggles facing multicultural students. One participant wrote,

"These students from multicultural families have a hard time in their sensitive teen years, just because of their skin color... We [educators] need to teach children that children from multicultural families are not any different from them.”

5.2 Research Question 2. How comfortable are South Korean pre-service teachers with the multiculturalization of South Korean society? Do pre-service teachers have any attitudes or perceptions of South Korean society that may prevent them from being competent in using multicultural approaches in education?

In order to understand if pre-service teachers might have any attitudes or perceptions that may prevent them from being competent in using multicultural approaches in education, we asked questions about the traditional identity of Danil Minjok and how comfortable they felt about the multiculturalization of South Korean society.

Pre-service teachers' perceptions of the notion of Danil Minjok were mostly negative. When asked, "Regarding the members of South Korean society, do you agree with the perception of Korea's national identity as Danil Minjok?”, most respondents disagreed, with over 11.1 percent (9) and 60.5 percent (49) of the respondents strongly disagreeing or disagreeing with the Danil Minkok identity, while only 3.7 percent (3) and 24.7 percent (20) strongly agreed or agreed. This is a notable finding, given that while these pre-service teachers were in school, all South Korean textbooks, including history, literature, and citizenship education, emphasized South Korea's history of a one-blood ethnicity.

In contrast to the responses regarding the notion of Danil Minjok, it appeared that many respondents reported that they did not feel comfortable with the multiculturalization of South Korean society. The majority of respondents (47.6\%) indicated that they felt undecided about multiculturalization. Many respondents indicated in their written responses that because they did not have much real life experience with diversity, they did not have many opportunities to truly reflect on how they felt about the change in society. Only around 20 percent expressed that they feel comfortable or very comfortable, whereas over 31 percent responded that they feel uncomfortable or very uncomfortable. 
Table 2. Responses for questionnaire item: How comfortable do you feel about the multiculturalization of South Korean society?

\begin{tabular}{|l|c|c|}
\hline & Percentage & Count \\
\hline Feels very natural and comfortable & $2.4 \%$ & 2 \\
\hline Feels natural and comfortable & $18.3 \%$ & 15 \\
\hline Undecided & $47.6 \%$ & 39 \\
\hline Feels unnatural and uncomfortable & $30.5 \%$ & 25 \\
\hline Feels very unnatural and uncomfortable & $1.2 \%$ & 1 \\
\hline
\end{tabular}

5.3 Research Question 3. What attitudes and perspectives do South Korean pre-service teachers have about multicultural education?

For research question 3, we asked pre-service teachers how important multicultural education is and what the purpose of multicultural education should be. We also asked whom multicultural education should be for, and what kind of instructional approaches should be used for multicultural education.

In response to the question of how important multicultural education is in South Korean K-12 education, 96.2 percent of pre-service teachers agreed that it was important or very important. Only 3.7 percent responded that multicultural education was of average importance. These responses were consistent with the majority of pre-service teachers indicating their concern about how poorly immigrants are treated in South Korean society and how the children from multicultural families are struggling in schools.

Table 3. Responses for questionnaire item: How important is multicultural education in South Korean K-12 school education?

\begin{tabular}{|l|c|c|}
\hline & Percentage & Count \\
\hline Very important & $60.5 \%$ & 49 \\
\hline Important & $35.8 \%$ & 29 \\
\hline Average & $3.7 \%$ & 3 \\
\hline Unimportant & $0 \%$ & 0 \\
\hline Very unimportant & $0 \%$ & 0 \\
\hline
\end{tabular}

In response to the question about whom multicultural education should be for, respondents wrote that multicultural education was primarily for all members of South Korean society. Others stated that it was for the world (in a global sense), and some stated that it was for "Korea's future generation and therefore should focus on elementary level students in particular". Finally, there were respondents that felt it was primarily for students from multicultural families to become more competent and comfortable in South Korean society and therefore should focus on finding ways to support them.

Pre-service teachers' perspectives on the purpose of multicultural education also varied. Respondents voiced what Sleeter and Grant (2007) called a "human-relations" approach that promotes a sense of harmony and unity among different groups. They thought that the purpose of multicultural education was to help students grow as individuals who are able to 
understand and embrace other cultures, countries and races/ethnicities, so that "we can have a happy and harmonious South Korean society". Some notable responses included the following:

"Multicultural education is for our culture to develop not only our 'traditional South Korean culture' but to also facilitate the development of 'other cultures' in our society as well.” and

"Multicultural education is to create a society that does not only include the minorities who are assimilative and harmonious but also those who are not”.

Multicultural education as a tool to improve the nation's competitiveness in the global market was also identified as instrumental. These respondents felt that multicultural education was critical for South Korea to "stay economically and culturally stable and competitive in the global world". Finally, pre-service teachers also saw it as a tool to improve classroom climate. They voiced the importance of aiming for specific goals that could help change mono-cultural Korean children's behaviors in schools, so they would be more respectful towards multicultural classmates.

On what kind of approaches schools should be using for multicultural education, pre-service teachers responded that an approach utilizing interdisciplinary and authentic, real life experiences would be most effective. One participant wrote,

"We need to let them understand multiculturalism through an authentic experience... we need to have all our children really see the struggles of multicultural families and to have the students experience that all people are the same."

These respondents felt that the best way to help students was to facilitate "fundamental change in their attitudes".

Pre-service teachers voiced that in school, social studies or ethics education should be the subject to have a curriculum for multicultural education. The need for the South Korean Ministry of Education to have ongoing public advertisements and local community multicultural education programs was expressed as well. These responses stressed that South Korea's perspective on multiculturalism had to change altogether, rather than only in schools.

At the same time, there were some negative, or cautionary responses to multicultural education as well.

"In a way, multicultural education can be worse because it draws more attention to them [children from multicultural families]. Natural assimilation is best without emphasizing the difference”

"Because prejudice is so entrenched in our society, multicultural education will not make a difference even if we try. The adults need to change their mindsets first. That is more important.” 
These respondents mostly felt that the push for multicultural education in schools could produce unintended side effects.

5.4 Research Question 4. How prepared do South Korean pre-service teachers feel about teaching in classrooms with diversity and addressing multicultural issues? What kinds of preparation, training or support do pre-service teachers want for using multicultural approaches in the classrooms?

In order to understand how prepared South Korean pre-service teachers feel about teaching in classrooms with diversity, we asked whether they had ever used multicultural approaches in their student teaching or field experiences, and if so, how they were used. We also asked how South Korean pre-service teachers could be better prepared, trained or supported to effectively use multicultural approaches in teaching.

Out of 82 respondents, 63.6 percent (53) of respondents responded that they have not been able to experience or be in a setting to use or learn multicultural approaches for teaching. Only 35.3 percent (29) of the participants responded that they had been in a teaching or mentoring situation that called for multicultural approaches, most of which were very minimal and abstract activities.

The activities described in the narratives were similar to the responses from research question 1 , such as traveling or volunteering for missionary work in different countries which gave them the opportunity to interact with people from different cultures and appreciate differences while finding what they had in common. Doing volunteer work at community centers or churches in their local communities were also opportunities these pre-service teachers had. Those who had participated in the government supported multicultural mentoring program at the university described how they had meetings and attended “Children's Day” events with children of multicultural families. Again, these meetings were open to all students, as the program did not want to promote stigma and differentiation.

Some respondents, who never had a chance to apply multicultural approaches in authentic situations, shared how they would like to apply them in their future classrooms. One secondary music pre-service teacher wrote of her desire to have students attend concerts or engage in discussions related to music from different cultures. Other participants shared ideas for going on field trips where they as teachers would be able to model desired behavior when interacting with minorities in South Korean society. As discussed earlier in research question 3 , pre-service teachers seemed to think the best way to apply multicultural approaches in schools was through interdisciplinary and authentic life experiences.

There were respondents who were skeptical about the effectiveness of multicultural education as well. These respondents did not feel as hopeful about the role multicultural education could play in the larger society, such as,

"It's too large of a project for educators to take on for now in schools... it's the teachers who need to be educated first, not the students", or 
"We [South Korean society] are not ready. So it [multicultural education in schools] should be implemented with a teacher-centered approach rather than a student centered experience”.

In response to the question on how South Korean pre-service teachers could be better prepared to use multicultural approaches in teaching, responses fell into three categories: (a) government-led support, (b) teacher training and stitutional support, and (c) teachers' individual efforts.

Respondents emphasized the need for the government to lead curriculum revision for all subjects having a fundamental multicultural focus. The administrative support for media resources and introductory textbooks for all teachers was also a reoccurring response.

As for teacher training and institutional support, respondents focused on the need for required training, modeling, field experiences and interdisciplinary learning. They stressed that it would be beneficial to implement multicultural education course requirements during their teacher training. They suggested these courses also require pre-service teachers to enroll in field experiences specifically for interacting with immigrants and internationally married women and children from multicultural families. They pointed out that subjects such as music, art or literature could be a good way to understand different cultures and that these different subjects should implement multicultural approaches in their methods courses as well.

In addition, pre-service teachers talked about how the South Korean teaching force itself should be more diversified as well. One of them wrote,

"If we teach children from multicultural backgrounds, we should have more teachers from multicultural backgrounds in our schools as well”.

Finally, many respondents pointed to the fundamental paradigm shift that was needed in every individual teacher and the responsibility that teachers had in leading South Korean society to shift its mindset. They noted that teachers had the responsibility to push themselves to have progressive minds in order to apply multicultural approaches in classrooms and lead society to a better future.

\section{Discussion}

Two themes are identified in the results of the study: (a) the pre-service teachers have mixed feelings regarding the demographic shift in South Korea, and (b) they felt underprepared and under-resourced as multicultural educators. With these two themes in mind, we argue that multicultural education for pre-service teachers must prepare them to become active participants in the political process of schooling for social justice by challenging the myth of "we Koreans" and empower them to consider the meaning and implementation of multicultural education in their future teaching.

On one hand, the responses showed clearly that they were aware of the difficulties cultural and ethnic minorities were facing in South Korean society. This was a direct contradiction to Sleeter's (2008) findings on White pre-service teachers who denied the existence of racism today. More than 71 percent of the participants felt that cultural and ethnic minorities were 
unfairly treated in South Korean society. Many respondents were also aware that the students from multicultural families were struggling in schools. The awareness of minorities and their children's challenging situations was leading pre-service teachers to feel a sense of responsibility as educators. Many responses were based on the assumption that "we are educators, therefore we need to do something to change this situation". There was a very strong sense of responsibility of teachers in leading South Korean society to a better future. The pre-service teachers were responding to these social expectations of South Korean society, where teachers are respected and expected to lead the society with progressive energy.

While the pre-service teachers were feeling responsibility towards being a critical part of South Korean society in overcoming these challenges, they also shared that they did not necessarily feel comfortable with the rapid multiculturalization of South Korean society yet. Over 31 percent of respondents said that they did not feel comfortable while over 40 percent said that were not very sure how they felt. The difference in the perspectives on multicultural education between the undergraduate pre-service teachers and those in the graduate level teacher certification program were also made visible through the analyses. Younger pre-service teachers who were between 19-24 were far more open and reflective towards multicultural issues in both society and schools. They felt more comfortable about multiculturalization in South Korean society and were also strongly disagreeing with the idea of Danil Minjok, while pre-service teachers in the 25-39 age category were far less comfortable about multiculturalization and agreed with the idea of Korea's pride of one-blood ethnicity.

The discrepancy between their recognition of the problem and personal ambivalence towards the topic must be addressed in the studying of multicultural education during teacher training. This version of multicultural education extends beyond celebrating and understanding culturally different others and requires what Gorski (2006) calls "politicalization" of multicultural education, where the goal of multicultural education is transforming one's own community and society. One way to do this is to explore the process through which the myth of Danil Minjok is constructed and maintained in schools. Preservice-teachers must critically examine the social process through which the notion of "we Koreans" eventuates in the privileges and disadvantages for themselves and their future students both in and out of schools. This would challenge the pre-service teachers to critically reflect upon how their own personal attitudes may help or hinder their sense of being responsible teachers who can improve society through schooling. This version of critical multiculturalism seeks to orient the pre-service teachers' personal and professional attitudes towards promoting a sense of fairness and justice for both multicultural and mono-cultural students in South Korea.

The second theme is the confusion on the concept of multicultural education. Pre-service teachers were not sure what multicultural education is or what it should be in the South Korean context. The most common comments of confusion were with the concepts of peace education or global citizenship education. Some respondents made comments of how international education, such as learning about different countries and celebrating other cultures and their traditions is possibly the only instructional method of multicultural 
education. Others reduced multicultural education to mean, "field experiences" where teachers interact with people of different cultures in Korea. Several comments showed pre-service teachers' confusion of multicultural education with peace education in the South Korean context, which in many cases focused solely on the North and South Korean divide, conflict and the need for reunification in the future. The confusion over the definition of multicultural education can be seen as a form of resistance to critical multiculturalism in schools. Some respondents felt that the push for multicultural education in schools could make bullying or wangtta worse, as it could highlight the differences among children and produce stigma. These pre-service teachers thought quiet and natural assimilation could be a better solution. Similarly, some respondents felt that despite the society's clear need to change, it was too large of a paradigm change for teachers to make an impact on. Others shared the feeling of helplessness in the fact that they did not have the resources or training to use multicultural approaches in their future classrooms.

The confusion of what multicultural education is and how to implement it reported here presents an opportunity for critical multiculturalism that seeks to empower educators to define multicultural education with their students in their own practice. Regarding the teacher-student relationship, Freire (1999) argues, "Education must begin ... by reconciling the poles of contradictions so that both [students and teachers] are simultaneously students and teachers (p. 72). Put differently, critical multicultural educators reject the teacher-student dichotomy where an authoritative figure teaches knowledge to passive learners but instead embrace a reciprocal relationship in learning. In such a relationship, both a teacher and students become active members of a learning community with an aim to bring the social process of domination into the light as a way to critique and challenge (Kincheloe, 2008; Freire 1999). This view empowers pre-service teachers to define multicultural education both individually and as a group. In the process, critical multicultural education allows pre-service educators to view themselves as capable and competent professional educators who create knowledge and encourages them to view their future students as potential allies in their shared struggles towards social justice.

What we found, however, was that the respondents depended on the guidance of politicians to define the concept of multicultural education. For instance, the respondents articulated that a strong national curriculum was needed that would set clear goals, values and norms in schools, and that they would really like a resource packet that contains multimedia resources on multicultural education that they could use in classrooms. The political reality for South Korean educators is that their profession is subjected to a very centralized educational policy for any type of program or plan in schools. The centralized policy implementation could be positive in creating a foundation for multicultural education and implementing programs and professional development opportunities to train educators for multicultural approaches in schools. However, the centralized approach to multicultural education falls short in fostering the range of possible approaches to multicultural education. Moreover, it reduces educators to deliverers of knowledge and discourages them from challenging the central policy or exploring alternatives. With this in mind, we argue that multicultural education in South Korea must empower pre-service teachers to actively engage in defining multicultural 
education in their own contexts as a way to politically engage multiculturalism both in and out of school. Pre-service teachers must learn to value their own voices and appreciate diverse perspectives so that they can value and appreciate culturally different students in their future classrooms.

\section{Conclusion}

The South Korean cultural landscape is already moving towards more diversity. According to a recent poll done by The Korean Times, almost 70 percent of South Koreans support the idea of promoting and safeguarding cultural diversity through a constitutional amendment (Lee, 2010). When asked whether the nation's constitution should add a clause that South Korea encourages cultural diversity to reflect the country's changing demographics, 69.8 percent of the surveyed expressed their support, while only 20.1 percent of the 1,000 respondents opposed the idea and 10.1 percent replied that they were unsure (Lee, 2010). While these numbers are a populist result of a newspaper poll, the popular culture and mainstream society of South Korea is clearly moving towards the direction of being open to a multicultural Korea, and South Korean educators must be prepared to meet the demands and challenges of the new Korea.

In conclusion, this article examined South Korean pre-service teachers' attitudes towards the increasing diversity and multicultural education in South Korean schools via a set of survey questions. The result was that the pre-service teachers held conflicting views toward the topic and were generally unsure about the concept of multicultural education. Looking at the responses through the lens of critical multiculturalism, we argued the pre-service teachers in South Korea must be challenged to critique the process through which dominance is constructed and maintained, examine their own positionalities to this process, and redefine their relationship to learning. More specifically, we argue that multicultural education for South Korean pre-service teachers must critique the myth of Danil Minjok while contextualizing the resulting privileges and disadvantages and empower them to define multicultural education on their own terms to best serve multicultural and mono-cultural students.

One research implication of this study is the strong need for a variety of research studies in South Korean school settings that take a look at the academic and school life challenges facing multicultural students as well as their teachers' and administrators' struggles in supporting these students. As noted earlier, the pre-service teachers acknowledged that they are aware of the unfair treatment that multicultural individuals face. It was unclear, however, if they grasped the complexity of the struggles or understood the impact of it on the entire school community at large. Narratives told by the multicultural students and their teachers regarding their own school experiences may better prepare the pre-service teachers for multicultural education as discussed here. Also, a similar study that looks at the attitudes towards diversity and the understanding of multicultural education held by current teachers would be useful as well. Such a study would inform the nature of professional development programs in order to meaningfully incorporate multicultural education into practice in South Korean schools. 


\section{Acknowledgment}

This research study was funded by a grant from the Benjamin V. Cohen Peace Fellowship Program.

\section{References}

Castro, A. J. (2010). Themes in the research on perservice teachers' views of cultural diversity: Implications for researching millennial preservice teachers. Educational Researcher, 39(3). 198-210. doi:10.3102/0013189X10363819, http://dx.doi.org/10.3102/0013189X10363819

Cho, Y. (2006). Survey on education of the children of multicultural families. Korea: Policy Report of Ministry of Education and Human Resources.

Choi, J. (2010). Educating citizens in multicultural society: The case of South Korea. Social Studies, 101, 174-179 doi:10.1080/0037799090328415, http://dx.doi.org/10.1080/0037799090328415

Freire, P. (1999). Pedagogy of the oppressed (30 ${ }^{\text {th }}$ anniversary ed.). New York: Continuum.

Gay, G. (1995). Mirror images on common issues: Parallels between multicultural education and critical pedadogy. In C. E. Sleeter, C. E. \& P. McLaren, (Eds.), Multicultural education, critical pedagogy, and the politics of difference (pp. 155-189). Albany: State University of New York Press.

Gorski, P. C. (2006). Complicity with conservatism: The de-policalizing of multicultural education and intercultural education. Intercultural Education, 17(2), 163-177. doi:10.1080/14675980600693830, http://dx.doi.org/10.1080/14675980600693830

Kang, S. (2010). Multicultural education and the rights to education of migrant children in South Korea. Educational Review, 62(3), 287-300. doi:10.1080/00131911.2010.503599, http://dx.doi.org/10.1080/00131911.2010.503599

Kang, S. (2008). Tasks of multicultural education based on UK inclusive education policy. Journal of Education for International Understanding, 3, 5-44.

Kincheloe, J. L. (2002). Teachers as researchers: Qualitative paths to empowerment (2 ${ }^{\text {nd }}$ ed.). New York: Routledge Falmer.

Kincheloe, J. L. (2008). Knowledge and critical pedagogy: An introduction. Dordrecht, London: Springer. doi:10.1007/978-1-4020-8224-5_1, http://dx.doi.org/10.1007/978-1-4020-8224-5_1

Kong, D., Yoon, K, and Yu, S. (2011). The social dimensions of immigration in Korea. Journal of Contemporary Asia, 40(2), 252-274.

Lee, J. (2002). Analytical research on the mental and emotional development of pupils. Seoul: Korean Educational Development Institute. 
Lee, T. H. (2010). 70\% of Koreans hope to embrace multicultural society. The Korean Times. [Online] Available: http://www.koreatimes.co.kr/www/news/nation/2010/10/113_75523.html

Lee, Y., Seol, D., \& Cho, S. (2006). International marriages in South Korea: The significance of nationality and ethnicity. Journal of Population Research, 23(2), 165-182. doi:10.1007/BF03031814, http://dx.doi.org/10.1007/BF03031814

Lim, T. (2010). Rethinking belongingness in Korea: Transnational migration, "migrant marriages” and the politics of multiculturalism. Pacific Affairs, 83(1), 51-71.

Ministry of Education and Human Resources (MEHR). (2008). Supportive action plan of education for children from multicultural families. Seoul, Korea: MEHR.

Oh, S. (2005). A case study on growth and environment of the Kosian children. Korean Education, 32(3), 61-83.

Park, H. (2007). Linguistic human rights of Asian migrant workers in South Korea. The International Journal of Human Rights, 11(4), 445-460. doi:10.1080/13642980701659971, http://dx.doi.org/10.1080/13642980701659971

Park, K. (2005). Minority and Korean society. Seoul, Korea: Humanitas.

Rodriguez, A. J. (1998). Strategies for counterresistance: Towards sociotransformative constructivism and learning to teach science for diversity and for understanding. Journal of

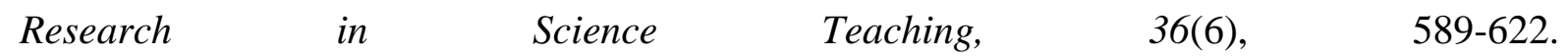
doi:10.1002/(SICI)1098-2736(199808)35:6<589::AID-TEA2>3.0.CO;2-I, http://dx.doi.org/10.1002/(SICI)1098-2736(199808)35:6<589::AID-TEA2>3.0.CO;2-

Rodriguez, A. J., and Berryman, C. (2002). Using sociotransformative constructivism to teacher for understanding in diverse classrooms: A Beginning teacher's journey. American Educational Research Journal, 39(4), 1017-1045. doi:10.3102/000283120390041017, http://dx.doi.org/10.3102/000283120390041017

Sleeter, C. E. (2008). Preparing White teachers for diverse students. In m. Cochran-Smith, S. Feiman-Nemser, \& D. J. McIntyre (Eds.), Handbook of research on teacher education: Enduring questions in changing contexts ( $3^{\text {rd }}$ ed., pp. 559-582). New York: Routledge and Association of Teacher Educators.

Sleeter, C. E., \& Grant, C. A. (2007). Making choices for multicultural education: Five approaches to race, class, and gender ( $5^{\text {th }}$ ed.). San Francisco: Jossey-Bass.

Sul, D., Han, G., and Lee. J. (2003). Survey on human rights situation of the children from foreign workers in Korea. Seoul: National Commission for Human Rights.

Villegas, A. M., \& Lucas, T. (2002). Educating culturally responsive teachers: A coherent approach. Albany: State University of New York Press.

Vogt, P.W. (2007). Quantitative Research Methods for Professionals. Boston, Massachusetts: Allyn and Bacon. 


\section{Macrothink}

Yoon, I. (2004). Korean Diaspora. Seoul, Korea: Korea University Press.

Yoon, M. (2007). Black Happiness. On Yoonmirae [CD]. Seoul: Phantom Entertainment.

\section{Copyright Disclaimer}

Copyright reserved by the author(s).

This article is an open-access article distributed under the terms and conditions of the Creative Commons Attribution license (http://creativecommons.org/licenses/by/3.0/). 